DOI: $10.20472 / \mathrm{IAC} .2017 .032 .035$

\author{
JIRI PROCHAZKA \\ University of Economics, Prague, Czech Republic \\ MATEJ CAMAJ \\ University of Economics, Prague, Czech Republic
}

\title{
MODELLING THE NUMBER OF ROAD ACCIDENTS OF UNINSURED DRIVERS AND THEIR SEVERITY
}

\begin{abstract}
:
The main aim of the presentation is to discuss methods which can be used for modelling the number of daily road accidents of uninsured drivers and their claim severity i.e. the average claim per accident. Modelling of such events is relevant for institutions such as the insurance companies, national insurers' bureau etc. The proposed model consists of three parts. The first part models deterministic seasonality with special focus given on daily seasonality. Daily seasonality is usually considered as seasonality with long seasonal period, so we will use approaches based on basis expansion. The second part characterizes the impact of other deterministic variables such as long-term trend and other external variables. The last part of the model is an error term part the purpose of which is to capture residual randomness of the model. Because of the character of the time series, GARMA model will be used to capture the error term part.
\end{abstract}

\section{Keywords:}

road accidents; long seasonal period modelling; basis expansion; GARMA models

JEL Classification: C53, G22 